|| ISSN(online): 2589-8698 || ISSN(print): 2589-868X ||

International Journal of Medical and Biomedical Studies

Available Online at www.ijmbs.info

NLM (National Library of Medicine ID: 101738825)

Index Copernicus Value 2019: 79.34

Original Research Article

Volume 5, Issue 6; June: 2021; Page No. 222-225

\title{
TO EVALUATE COGNITIVE PERFORMANCE IN PATIENTS WITH CHRONIC KIDNEY DISEASE
}

\section{Dr. Saurabh Singhal}

Associate professor Dept. of Medicine KD Medical College and research centre Mathura UP

Article Info: Received 05 April 2021; Accepted 20 May 2021

DOI: https://doi.org/10.32553/ijmbs.v5i6.2001

Corresponding author: Dr. Saurabh Singhal

Conflict of interest: No conflict of interest.

\section{Abstract}

Background: In people with chronic kidney disease (CKD), cognitive decline is one of the major causes for poor outcome in terms of quality of life and survival rate. Previous studies have found an association between cardiovascular disease and psychiatric disorders in people with CKD. Physicians should keep in mind that the psychiatric changes and cognitive decline seen in all stages of CKD is to be detected early in the course of the disease, for timely management of it and for better outcome in terms of survival rate.

Aim: The goal of this study is to evaluate cognitive performance in patients with chronic renal disease

Material and Method: The study was conducted from March 2019 to april 2021 in department of general medicine and nephrology clinic at KDMCH, Mathura. Between March 2019 to april 2021, baseline data were obtained. The study included 108 participants (58 with CKD and 50 with ESKD). ESKD patients were 'CKD patients with dialysis'. Various tests were used to assess brain function.

Results: ESKD patients had significantly lower scores on the 3MS, TMT-A and TMT-B trials, with a difference between TMT-A and B than CKD patients. In ESKD patients, the numbers less than 3MS of speech and fluency memory, as well as visuo-position and structure, were significantly lower. ESKD patients had the highest number of patients with psychiatric disorders, as measured by the outpatient testing scores listed above 3MS, TMT-A, and TMT-B. ESKD patients had significantly higher levels of depression than CKD patients.

Conclusion: Higher cognitive decline was found in the ESKD group in comparision to non-dialysis CKD group. Also ESKD was associated with higher rates of cerebro-vascular disease, cardio-vascular disease and peripheral artery disease.

Keywords: Chronic Kidney Disease, ESKD, eGFR and cognitive impairment

\section{Introduction}

CKD is a growing public health issue. Kidney failure is common in people of all ages, but especially in adults. People with CKD at any stage are more likely to have a mental disability, which can be a major factor in their quality of life. In addition, among dialysis patients, cognitive decline was linked to an increased risk of death. Cerebrovascular disease is a major risk factor for impairment in the brain, and vascular disease is a greater cause of cognitive decline in people with CKD than Alzheimer's disease. CKD patients are more likely to experience chronic and abnormal vascular risk factors, and dialysis patients may be at risk for psychiatric complications due to non-vascular risk factors and the hemodialysis process itself. Unfortunately, because the risk factors for cognitive impairment in CKD are not yet fully known, treatment options are restricted. ${ }^{1}$

In chronic kidney disease, mental retardation is a major source of illness (CKD). People with a mental disability have a lower quality of life, have a harder time adhering to drugs, and have a lower chance of survival. ${ }^{2}$ Importantly, when kidney function declines, mental retardation is more widespread and severe. This is in line with an increase in mental disability from 30 to $70 \%$ among dialysis patients with kidney failure. ${ }^{3,4}$

The cause of mental retardation in patients with CKD may be many, indicating a variety of medical concerns these people are experiencing. Alzheimer's disease first affects memory and especially in elderly patients with kidney disease, as it does in most people; However, the levels of Alzheimer's disease in CKD patients look similar to those in the control and age and gender levels, so there is no explanation for the increase in cognitive impairment. ${ }^{5}$ most of all. Even for those who do not have a well-known history of stroke, the concept of magnetic resonance imaging in dialysis patients shows significant burden of white matter, atrophy, and cerebral infarcts. ${ }^{6}$

The increase in the incidence of cognitive impairment in patients with advanced $\mathrm{CKD}^{7}$, compared with those with previous stages, suggests that cognitive decline is expected to increase over time in this population, associated with CKD and chronic vascular's trajectory. However, such progress may be marginalized, as cognitive function in the CKD group has been shown to remain stable over a period of two years. ${ }^{8}$ On the other hand, the potential benefits of removal of uremic poison from dialysis compared with the 
potential risk of cerebral ischemia over the time with hemodialysis and the gradual progression of cerebrovascular disease may create a medium-term increase in cognitive function in ESKD patients undergoing dialysis. $^{9}$

In this study, we hypothesized that ESKD patients would have a lower cognitive function and a faster rate of mental retardation than CKD patients. The aim of this study was to evaluate the cognitive performance of the patients with CKD and ESRD.

\section{Material and Methods}

The study was conducted from March 2019 to april 2021 in department of general medicine and nephrology clinic at KDMCH, Mathura. Between March 2019 to april 2021, baseline data were obtained. The study included 108 participants (58 with CKD and 50 with ESKD). ESKD patients were 'CKD patients with dialysis'. Various tests were used to assess brain function.

To avoid any mental variability associated with dialysis treatment, diagnostic instruments were given to ESKD patients receiving hemodialysis before or during the first hour of dialysis. It has been shown that psychiatric functioning does not differ significantly from one-hour prehemodialysis tests and one-hour screening of hemodialysis. ${ }^{10}$ Simultaneous screening of non-dialysis CKD patients and external dialysis patients reduces the need for more frequent nephrology clinics.

Patients had to be eighteen years of age or older, have chronic kidney disease, and be able to give informed consent. Patients with ESKD need to undergo dialysis at least three months prior to enrollment to ensure that their clinical and chemical conditions are stable.

\section{Data collection}

After obtaining written consent from study participants, study assistants used a combination of patient interviews and medical record reviews to collect demographic information (age, gender, race, educational status, income), smoking status, and clinical data, such as cause of renal disease and comorbidities (diabetes, high blood pressure, hyperlipidaemia, and coronary artery disease).

\section{Inclusion and exclusion criterion}

Patients were excluded if they had received a kidney transplant or were actively involved in a live donor transplant; he had dementia or mental retardation; have a minimum medical life span of less than 12 months based on their comorbidities.

The ethics committee has approved the approval process, as well as consent forms and assessment instruments. Patients were removed from the case where a condition of discharge was obtained after an informed consent was signed.

\section{Result:}

125 eligible people were invited to participate in the study (65 with CKD and 60 with ESKD). Four patients were excluded because they did not meet the inclusion procedure, and 13 patients were excluded from the study due to withdrawal of permission, kidney transplant, or death prior to collecting basic data. This resulted in a follow-up group of 108 patients (58 CKD, 50 ESKD). ESKD patients who completed follow-up tests had a vintage dialysis less than one year (3-12 months) in 28 of the 90 patients (30\%), and $52(90 \%)$ had been on dialysis for more than a year at baseline.

Table 1: The research population's baseline demographic and clinical features were compared between CKD and ESKD patients.

\begin{tabular}{|l|l|l|l|}
\hline & $\begin{array}{l}\text { Overall Population } \\
\text { Mean } \pm \text { SD\% }\end{array}$ & $\begin{array}{l}\text { CKD Patient } \\
\text { Mean } \pm \text { SD\% }\end{array}$ & $\begin{array}{l}\text { ESKD Patient } \\
\text { Mean } \pm \text { SD\% }\end{array}$ \\
\hline No. of patients & $\mathbf{1 0 8}$ & $\mathbf{5 8}$ & $\mathbf{5 0}$ \\
\hline Smoking status & $72.6 \pm 14.8$ & $69.7 \pm 11.4$ & $65.2 \pm 12.9$ \\
\hline Diabetic Nephropathy & $38.4 \%$ & $32.8 \%$ & $41.2 \%$ \\
\hline Hypertension & $24.2 \%$ & $30.7 \%$ & $18.4 \%$ \\
\hline Ischemic heart disease & $43.8 \%$ & $28.4 \%$ & $58.5 \%$ \\
\hline Peripheral vascular disease & $26.8 \%$ & $11.2 \%$ & $39.7 \%$ \\
\hline Lung disease & $32.4 \%$ & $29.3 \%$ & $35.9 \%$ \\
\hline Cerebrovascular disease & $18.7 \%$ & $13.6 \%$ & $21.4 \%$ \\
\hline
\end{tabular}

The study population was 65 years on average, and ESKD patients (65 years) were younger than CKD patients (66years). The majority of ESKD and CKD patients $(61 \%)$ were male, and education levels were similar in both subgroups. Ischemic heart disease and peripheral vascular disease have been shown to be more common in ESKD patients, who had diabetic nephropathy as a cause of kidney disease. Among the groups of CKD and ESKD patients, smoking status and increased comorbidities such as diabetes, high blood pressure, cerebrovascular disease, and lung disease were compared. 
Table 2: The cognitive function and depression baseline values.

\begin{tabular}{|l|l|l|l|}
\hline Test Instrument used to measure cognitive functions. & $\begin{array}{l}\text { Overall Population } \\
\text { Mean } \pm \text { SD }\end{array}$ & $\begin{array}{l}\text { CKD Patient } \\
\text { Mean } \pm \text { SD }\end{array}$ & $\begin{array}{l}\text { ESKD Patient } \\
\text { Mean } \pm \text { SD }\end{array}$ \\
\hline Score on the Modified Mini Mental State Examination (3MS) & $95.8 \pm 7.3$ & $98.2 \pm 6.7$ & $91.4 \pm 8.1$ \\
\hline 3MS verbal memory\& fluency domain & $28.4 \pm 4.1$ & $31.6 \pm 3.8$ & $27.9 \pm 4.8$ \\
\hline 3MS orientation \& visuo- construction domain & $22.4 \pm 2.2$ & $20.6 \pm 0.86$ & $21.8 \pm 3.5$ \\
\hline 3MS Language- praxis domain & $12.4 \pm 0.6$ & $12.8 \pm 0.9$ & $11.4 \pm 0.3$ \\
\hline 3MS Language and executive function domain & $18.7 \pm 3.4$ & $18.9 \pm 3.8$ & $17.5 \pm 2.5$ \\
\hline Trail Making Test Part A & $51.2 \pm 35.7$ & $41.7 \pm 18.5$ & $65.9 \pm 46.8$ \\
\hline Trail Making Test Part B & $125.7 \pm 86.1$ & $102.8 \pm 62.8$ & $152.7 \pm 99.4$ \\
\hline
\end{tabular}

Initially, ESKD patients had significantly lower scores on the 3MS, TMT-A and TMT-B trials, with a difference between TMT-A and B than CKD patients. In ESKD patients, the numbers less than 3MS of speech and fluency memory, as well as visuo-position and structure, were significantly lower. ESKD patients had the highest number of patients with psychiatric disorders, as measured by the outpatient testing scores listed above 3MS, TMT-A, and TMT-B. ESKD patients had significantly higher levels of depression than CKD patients.

\section{Discussion}

Cognitive functions in ESKD patients were significantly lower than in non-dialysis CKD patients, consistent with previous studies. ${ }^{11,12}$ However, ESKD dialysis patients, especially those who had been on dialysis for less than a year, showed little decline in cognitive functions in comparision to those who were on dialysis for more than a year.

Seidel et al. ${ }^{13}$ conducted a cross-sectional study to assess psychiatric functioning in 119 patients with CKD and 54 healthy controls, all of which had a glomerular filtration rate of more than $60 \mathrm{ml} / \mathrm{min}$ per $1.73 \mathrm{~m} 2$ but otherwise risk factors. Seidel et al. ${ }^{13}$ Investigate the relationship between variability in cardiovascular risk and mental functioning. High hemoglobin A1c (HbA1c) was linked to poor cognitive function, even after controlling previous history of CVD cases and other traditional risk factors such as dyslipidemia, smoking, BMI, and systolic blood pressure. Although HbA1c was previously associated with psychiatric functioning in people with type 2 diabetes, this was not transmitted to patients with severe CKD.

Patients on dialysis who have cognitive impairment have a higher mortality risk, which leads to a higher rate of deathrelated drop-out. ${ }^{14,15}$ Non-mortality dropouts are known to be higher in cognitively impaired adults, and selective attrition and survival bias can sway any hypothesis in a longitudinal study. ${ }^{16}$

In our study, improvements between speech memory and a number of patient measurements in patients with a dialysis yield less than 12 months propelled improvements in $3 \mathrm{MS}$ schools in the small ESKD group. Because of the transition from a rare urinary condition to a minor uremic condition immediately after the start of dialysis surgery, it is likely that the physical benefits of an improved chemical profile will be most evident in the first year of dialysis. In our study, higher cognitive decline was found in the ESKD group along with higher rates of cerebro-vascular disease, cardio-vascular disease and peripheral artery disease.

Drew et al. ${ }^{17}$ did not find a link between the duration of dialysis and higher mental function impairment.

There are a few errors in our study. The number of control people for CKD patients, selected in the same area as the population and the study area, provided an opportunity to compare CKD patients with ESKD directly, allowing us to examine our point of view. We must keep in mind that only a small percentage of CKD patients progress to the point where they need ESKD dialysis, and that there is a natural imbalance in direct comparisons between CKD and ESKD patients. Significant signal differences between groups revealed this imbalance, and we used multivariate analysis to adjust for significant variables.

\section{Conclusion:}

Finally, we found that baseline score of cognitive function and higher performance was lower in ESKD patients than in CKD patients. However, we found that, compared with CKD patients, global cognitive statistics for ESKD patients and schools related to verbal memory and fluency improved over time, which was due to the development of patients with a dialysis yield of less than one year. These findings suggest that memory responds to chemical reactions, but other cognitive domains, such as administrative function, are strongly influenced by cerebro-vascular disease. In our study, higher cognitive decline was found in the ESKD group along with higher rates of cerebro-vascular disease, cardio-vascular disease and peripheral artery disease.

\section{References:}

1. Sharma A, Yabes J, Al Mawed S, Wu C, Stilley C, Unruh $\mathrm{M}$, et al. Impact of Cognitive Function Change on Mortality in Renal Transplant and EndStage Renal Disease Patients. Am J Nephrol. 2016;44(6):462-72

2. Griva K, Stygall J, Hankins $M$ et al. Cognitive impairment and 7-year mortality in dialysis patients. Am J Kidney Dis 2010; 56: 693-703 
3. Sarnak MJ, Tighiouart H, Scott TM et al. Frequency of and risk factors for poor cognitive performance in hemodialysis patients. Neurology 2013; 80: 471480.

4. Murray AM, Tupper DE, Knopman DS et al. Cognitive impairment in hemodialysis patients is common. Neurology 2006; 67: 216-223.

5. Seliger SL, Siscovick DS, Stehman-Breen CO et al. Moderate renal impairment and risk of dementia among older adults: the Cardiovascular Health Cognition Study. J Am SocNephrol 2004; 15: 1904 1911.

6. Drew DA, Bhadelia R, Tighiouart $\mathrm{H}$ et al. Anatomic brain disease in hemodialysis patients: a crosssectional study. Am J Kidney Dis 2013; 61: 271278.

7. Kurella M, Chertow GM, Fried LF, Cummings SR, Harris T, Simonsick E, et al. Chronic kidney disease and cognitive impairment in the elderly: the health, aging, and body composition study. J Am SocNephrol. 2005;16(7):2127-33

8. Gronewold J, Todica O, Seidel UK, Volsek M, Kribben A, Bruck H, et al. Cognitive Performance Is Highly Stable over a 2-Year-Follow-Up in Chronic Kidney Disease Patients in a Dedicated Medical Environment. PLoS One. 2016;11(11)

9. Findlay MD, Dawson J, Dickie DA, Forbes KP, McGlynn D, Quinn $\mathrm{T}$, et al. Investigating the Relationship between Cerebral Blood Flow and Cognitive Function in Hemodialysis Patients. J Am SocNephrol. 2019;30(1):147-58
10. Drew DA, Tighiouart H, Scott TM, Lou KV, Shaffi $\mathrm{K}$, Weiner DE, et al. Cognitive performance before and during hemodialysis: a randomized cross-over trial. Nephron ClinPract. 2013;124(3-4):151-8.

11. Drew DA, Weiner DE, Sarnak MJ. Cognitive Impairment in CKD: Pathophysiology, Management, and Prevention. Am J Kidney Dis. 2019;74(6):78290.

12. Murray AM, Tupper DE, Knopman DS, Gilbertson DT, Pederson SL, Li S, et al. Cognitive impairment in hemodialysis patients is common. Neurology. 2006;67(2):216-23.

13. Seidel UK, Gronewold $J$, Volsek $M$ et al. The prevalence, severity, and association with $\mathrm{HbAlc}$ and fibrinogen of cognitive impairment in chronic kidney disease. Kidney Int 2014; 85: 693-702.

14. Griva K, Stygall J, Hankins M, Davenport A, Harrison M, Newman SP. Cognitive impairment and 7 -year mortality in dialysis patients. Am J Kidney Dis. 2010;56(4):693-703.

15. Matthews FE, Chatfield M, Freeman C, McCracken $\mathrm{C}$, Brayne C. Attrition and bias in the MRC cognitive function and ageing study: an epidemiological investigation. BMC Public Health. 2004;4:12

16. Tripepi G, Jager KJ, Dekker FW, Zoccali C. Selection bias and information bias in clinical research. Nephron ClinPract. 2010;115(2):c94-9

17. Drew DA, Weiner DE, Tighiouart H, Duncan S, Gupta A, Scott T, et al. Cognitive Decline and Its Risk Factors in Prevalent Hemodialysis Patients. Am J Kidney Dis. 2017;69(6):780-7. 